\title{
BMJ Open Material, psychosocial and sociodemographic determinants are associated with positive mental health in Europe: a cross-sectional study
}

\author{
Stefanie Dreger, ${ }^{1}$ Christoph Buck, ${ }^{2}$ Gabriele Bolte ${ }^{1}$
}

To cite: Dreger S, Buck C, Bolte G. Material, psychosocial and sociodemographic determinants are associated with positive mental health in Europe: a cross-sectional study. BMJ Open 2014;4: e005095. doi:10.1136/ bmjopen-2014-005095

- Prepublication history for this paper is available online. To view these files please visit the journal online (http://dx.doi.org/10.1136/ bmjopen-2014-005095).

Received 20 February 2014 Revised 29 April 2014 Accepted 9 May 2014

CrossMark

\section{ABSTRACT}

Objectives: To investigate the association between psychosocial, sociodemographic and material determinants of positive mental health in Europe. Design: Cross-sectional analysis of survey data. Setting: 34 European countries.

Participants: Representative Europe-wide sample consisting of 21066 men and 22569 women aged 18 years and over, from 34 European countries participating in the third wave of the European Quality of Life Survey (2011-2012).

Outcome: Positive mental health as measured by the WHO-5-Mental Well-being Index, while the lowest $25 \%$ centile indicated poor positive mental health.

Results: The prevalence of poor positive mental health was $30 \%$ in women and $24 \%$ in men. Material, as well as psychosocial, and sociodemographic factors were independently associated with poor positive mental health in a Europe-wide sample from 34 European countries. When studying all factors together, the highest $\mathrm{OR}$ for poor positive mental health was reported for social exclusion (men: $\mathrm{OR}=1.73,95 \% \mathrm{Cl} 1.59$ to 1.90 ; women: $\mathrm{OR}=1.69$, $95 \% \mathrm{Cl} 1.57$ to 1.81 ) among the psychosocial factors. Among the material factors, material deprivation had the highest impact (men: $\mathrm{OR}=1.96,95 \% \mathrm{Cl} 1.78$ to 2.15; women: $\mathrm{OR}=1.93,95 \% \mathrm{Cl} 1.79$ to 2.08 ).

Conclusions: This study gives the first overview on determinants of positive mental health at a European level and could be used as the basis for preventive policies in the field of positive mental health in Europe.

\section{BACKGROUND}

According to the definition of the WHO mental health is a 'state of well-being in which the individual realises his skills, copes with the normal stresses of life, can work productively and fruitfully, and is able to make a contribution to his community'. ' Studies provide empirical support that mental health consists of two independent dimensions: mental ill-health and positive mental health

\section{Strengths and limitations of this study}

- Large dataset with comparable data across Europe.

- Overview of a broad range of material, psychosocial and sociodemographic determinants of positive mental health among people in Europe.

- Stratified analysis to take potential gender differences into account.

- No causal interpretation is possible because of cross-sectional nature of study.

- Response rate of the EQLS was lower than aspired and varied from more than $60 \%$ in Bulgaria, Cyprus, Malta, Poland and Slovakia to below $30 \%$ in Luxembourg and the UK.

(PMH) or mental well-being. ${ }^{2} 3$ Recent studies that have explicitly considered levels of $\mathrm{PMH}$ in populations have illustrated that good mental health is more than just the absence of disease, ${ }^{245}$ and that people can experience $\mathrm{PMH}$ even if diagnosed with a mental illness. ${ }^{3}$ This is because mental wellbeing or PMH and mental illness are caused by different factors. ${ }^{6}$ It has also been shown that low PMH is a risk factor for depression ${ }^{78}$ and absence of PMH has been associated with an increased risk of mortality. ${ }^{29}$

The study of PMH is relatively young and there is still discussion on a common definition of PMH or mental well-being. ${ }^{10}$ There are two (complementary) traditions in conceptualising well-being: the hedonic approach emphasises feeling good (happiness, pleasant affect, life satisfaction) whereas the eudaimonic approach focuses on optimal social and psychological functioning. ${ }^{5}$ A valid measure of PMH should include items that assess the hedonic and eudaimonic

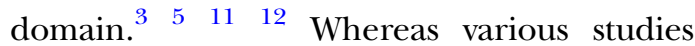
examined determinants of mental ill health, profound knowledge of determinants of $\mathrm{PMH}$ is lacking. PMH can be influenced by 
sociodemographic, psychosocial or material factors. ${ }^{13-16}$ However, until now studies that have focused on PMH have investigated only few determinants and looked at one country or at a very limited number of countries. Whereas prevalences of $\mathrm{PMH}$ in European countries have been reported before, ${ }^{17}$ no study so far has analysed a broad set of determinants of PMH considering a high number of European countries. The objective of our study was therefore to examine the association between sociodemographic, psychosocial and material factors and PMH at a European level taking gender differences into account.

\section{METHODS}

Sample

This study is based on the European Quality of Life Survey (EQLS), which is run every 4 years by the European Foundation for the improvement of living and working conditions. The third wave of the EQLS, which was carried out in 2011-2012, included people aged 18 years and older from 34 countries (EU-27, Croatia, Iceland, Montenegro, former Yugoslav Republic of Macedonia, Serbia, Turkey, Kosovo). In all countries, data were collected via face-to-face interviews at respondents' home, who were selected by multistage random sampling. The overall response rate was $41 \%$. A more detailed description of the EQLS 2012 can be found elsewhere. ${ }^{18}$

\section{Positive mental health}

Positive mental health was measured with the WHO-5Mental Well-being Index (WHO-5). ${ }^{19}$ It is calculated from responses to five items: (1) I have felt cheerful and in good spirits; (2) I have felt calm and relaxed; (3) I have felt active and vigorous; (4) I woke up feeling fresh and rested and (5) my daily life has been filled with things that interest me. The degree to which the aforesaid positive feelings were present in the past 2 weeks is scored on a six-point Likert scale ranging from 0 'at no time' to 5 'all of the time'. The scores to these five questions can total to a maximum of 25 , which is then multiplied by 4 to get to a maximum of 100 , where 0 corresponds with worst thinkable well-being and 100 equals best thinkable well-being. The WHO-5 is considered a valid instrument to evaluate $\mathrm{PMH}$ in populationbased studies ${ }^{20}$ and assesses PMH with items covering the eudaimonic perspective on well-being as well as items covering the hedonic dimensions of well-being. ${ }^{17}$ An average score of the index was calculated for the study population and those with values below the $25 \%$ centile were considered to have poor PMH.

\section{Potential determinants of PMH}

Three groups of determinants of PMH were studied: sociodemographic, psychosocial and material factors. This classification of determinants was inspired by studies that have used this classification in the field of self-rated health. ${ }^{21-23}$

Sociodemographic factors were age, educational level (categorised into three groups according to the International Standard Classification of Education), urbanisation level (living in rural/urban area) and citizenship (European/non-European). All these variables were categorical variables. Since potential risk factors might have different meaning for men and women, gender was not considered as a potential risk factor but as a structural variable and thus potential effect modifier. Therefore, all analyses were stratified by gender. ${ }^{24}$

Psychosocial factors were marital status, presence of children, social support (help from family/friends/neighbour/service provider in case of need for help around the house, advice, looking for a job, feeling depressed, financial problems; 5 items), social network (frequency of contact with family/friends/neighbours; 8 items), political participation (attended a meeting of a trade union/political party/political action group, attended protest or demonstration, signed a petition, contacted a politician/public official; 4 items), trust (in parliament/ legal system/press/police/government/local authorities; 6 items), religion (frequency of attending religious services), social exclusion (feelings of lack of recognition/ confusion in life/exclusion/inferiority; 4 items). Marital status, presence of children and religion were categorical variables. For social network, social support, political participation, trust and social exclusion, average scores were calculated and the median was used as cut-off point for the creation of dichotomised variables.

Material factors were household tenure, housing problems (shortage of space, rot in windows/doors/floors, damp/leaks in walls/roof, lack of bath or shower/ indoor flushing toilet, place to sit outside; 6 items), neighbourhood problems (noise/air pollution/quality of drinking water/crime/violence/vandalism/litter/ traffic; 6 items), material deprivation (not able to afford the following amenities/activities: heating/vacation/furniture/meal with meat, chicken, fish every second day/ new clothes/having friends and family for drinks or meals at least once a month; 6 items), financial problems (problems paying bills for rent/informal and consumer loans/electricity; 4 items), quality of public services (health services/education system/public transport/long-term care/child care services/state pension system/social housing; 6 items).

Household tenure was a categorical variable. Housing problems, neighbourhood problems, financial problems, material deprivation and quality of public services were dichotomised at the median of the average score of the items.

\section{STATISTICAL METHODS}

First, the distribution of sociodemographic, psychosocial and material factors was described separately for men 
Table 1 Percentages of men and women with poor positive mental health (PMH) by sociodemographic, psychosocial and material factors*

\begin{tabular}{|c|c|c|c|c|c|c|}
\hline & \multicolumn{3}{|l|}{ Men } & \multicolumn{3}{|l|}{ Women } \\
\hline & $\mathbf{N}$ & Per cent & Poor PMH (\%) & $\mathbf{N}$ & Per cent & Poor PMH (\%) \\
\hline \multicolumn{7}{|l|}{ PMH } \\
\hline Good & 15997 & 76 & & 15751 & 70 & \\
\hline Poor & 5069 & 24 & & 6818 & 30 & \\
\hline \multicolumn{7}{|l|}{ Sociodemographic factors } \\
\hline \multicolumn{7}{|l|}{ Age (years) } \\
\hline $18-24$ & 2707 & 13 & 16 & 2539 & 11 & 22 \\
\hline $25-34$ & 3919 & 19 & 21 & 3742 & 17 & 24 \\
\hline $35-49$ & 5847 & 28 & 25 & 5925 & 26 & 29 \\
\hline $50-64$ & 4932 & 23 & 27 & 5227 & 23 & 32 \\
\hline $65+$ & 3662 & 17 & 28 & 5136 & 23 & 38 \\
\hline \multicolumn{7}{|l|}{ Education } \\
\hline Primary or less & 1971 & 9 & 36 & 3090 & 14 & 44 \\
\hline Secondary & 13945 & 67 & 24 & 13983 & 62 & 30 \\
\hline Tertiary & 5004 & 24 & 19 & 5366 & 24 & 22 \\
\hline \multicolumn{7}{|l|}{ Working } \\
\hline Yes & 11494 & 55 & 20 & 8955 & 40 & 24 \\
\hline No & 9573 & 45 & 29 & 13614 & 60 & 34 \\
\hline \multicolumn{7}{|l|}{ Urbanisation level } \\
\hline Countryside or village & 9774 & 47 & 25 & 10325 & 46 & 31 \\
\hline Town or city & 11247 & 54 & 24 & 12187 & 54 & 30 \\
\hline \multicolumn{7}{|l|}{ Citizenship } \\
\hline European & 20509 & 98 & 24 & 22094 & 98 & 30 \\
\hline Non-European & 471 & 2 & 25 & 409 & 2 & 30 \\
\hline \multicolumn{7}{|l|}{ Psychosocial factors } \\
\hline \multicolumn{7}{|l|}{ Marital status } \\
\hline Living with partner & 11990 & 57 & 24 & 11678 & 52 & 28 \\
\hline Living alone & 8926 & 43 & 24 & 10749 & 48 & 32 \\
\hline \multicolumn{7}{|l|}{ Children } \\
\hline Present & 13065 & 62 & 26 & 16272 & 72 & 33 \\
\hline Absent & 8001 & 38 & 22 & 6297 & 28 & 24 \\
\hline \multicolumn{7}{|l|}{ Religion } \\
\hline Practicing often & 4831 & 23 & 25 & 6854 & 31 & 31 \\
\hline Rarely & 6875 & 33 & 23 & 7637 & 34 & 29 \\
\hline Never & 9255 & 44 & 24 & 7976 & 36 & 31 \\
\hline \multicolumn{7}{|l|}{ Social network } \\
\hline High & 4097 & 19 & 24 & 4563 & 20 & 31 \\
\hline Low & 16969 & 81 & 24 & 18007 & 80 & 30 \\
\hline \multicolumn{7}{|l|}{ Social support } \\
\hline High & 10070 & 48 & 21 & 10467 & 46 & 26 \\
\hline Low & 10996 & 52 & 27 & 12102 & 54 & 34 \\
\hline \multicolumn{7}{|l|}{ Political participation } \\
\hline Yes & 5410 & 26 & 21 & 4818 & 22 & 25 \\
\hline No & 15268 & 74 & 25 & 17380 & 78 & 32 \\
\hline \multicolumn{7}{|l|}{ Level of trust } \\
\hline High & 10359 & 49 & 18 & 10947 & 49 & 24 \\
\hline Low & 10708 & 51 & 30 & 11623 & 52 & 36 \\
\hline Social exclusion & & & & & & \\
\hline Low & 7800 & 37 & 16 & 8200 & 36 & 21 \\
\hline High & 13266 & 63 & 29 & 14369 & 64 & 35 \\
\hline Material factors & & & & & & \\
\hline Neighbourhood problems & & & & & & \\
\hline Low & 8024 & 38 & 21 & 8547 & 38 & 27 \\
\hline High & 13043 & 62 & 26 & 14022 & 62 & 32 \\
\hline Housing problems & & & & & & \\
\hline Absent & 13381 & 64 & 20 & 13893 & 62 & 25 \\
\hline
\end{tabular}




\begin{tabular}{|c|c|c|c|c|c|c|}
\hline & \multicolumn{3}{|l|}{ Men } & \multicolumn{3}{|l|}{ Women } \\
\hline & $\mathbf{N}$ & Per cent & Poor PMH (\%) & $\mathbf{N}$ & Per cent & Poor PMH (\%) \\
\hline Present & 7499 & 36 & 31 & 8455 & 38 & 39 \\
\hline \multicolumn{7}{|c|}{ Household tenure } \\
\hline Tenant & 14606 & 75 & 23 & 15997 & 76 & 30 \\
\hline Owner & 4832 & 25 & 25 & 5059 & 24 & 30 \\
\hline \multicolumn{7}{|c|}{ Material deprivation } \\
\hline Absent & 9843 & 51 & 14 & 8991 & 43 & 18 \\
\hline Present & 9592 & 49 & 33 & 11829 & 57 & 38 \\
\hline \multicolumn{7}{|c|}{ Financial problems } \\
\hline No & 16207 & 77 & 21 & 17379 & 77 & 27 \\
\hline Yes & 4859 & 23 & 35 & 5191 & 23 & 41 \\
\hline \multicolumn{7}{|c|}{ Quality of public services } \\
\hline Good & 5699 & 27 & 17 & 6241 & 28 & 21 \\
\hline Poor & 15367 & 73 & 27 & 16329 & 72 & 34 \\
\hline
\end{tabular}

*Product of the design weight and the post-stratification weight was applied.

and women, and the percentage of poor PMH was reported for each category.

We performed random intercept multilevel logistic regression analyses to examine the association between the potential determinants and PMH.

Multilevel models are particularly appropriate for research designs where data for participants are organised on more than one level to take into account the between-variability and within-variability of these hierarchically organised data (individuals, region, country). ${ }^{25}$ The model contains a so-called fixed part and a random component. Individual determinants were introduced as fixed effects, and country and region were used as random intercepts in the multilevel analysis taking into account three levels of data: individuals (level 1) nested in 330 regions (level 2), which are nested in 34 countries (level 3). Three separate models for women and men were computed to study the association between the groups of determinants (sociodemographic, psychosocial and material factors) and $\mathrm{PMH}$ independently (models 1-3). After that, all variables that were significant at $\alpha=0.05$ for at least one gender were included in the final model (model 4). Median ORs (MOR) were computed to quantify the country-level variation. MOR is defined as the median value of the OR between the country at highest risk and the country at lowest risk when randomly picking out two countries. $^{26}$ The MOR equals 1 if there is no variation between countries and gets larger if the between-country variation increases. ${ }^{27}$ The measure is directly comparable with fixed-effects ORs. ${ }^{27}$

Although inter-relations between factors were found, no collinearity was detected as the variance inflation factor was never greater than 1.9. Variance inflation factors greater than 2.5 may be problematic. ${ }^{28}$

Since determinants of PMH have only rarely been studied, no literature on potential interactions was available. However, gender differences have been suggested in this context ${ }^{1429}$ and men and women have different life circumstances. Therefore, we studied men and women separately.

All statistical analyses were conducted using SAS statistical software V.9.3. The product of the design weight and post-stratification weight was used as the weighting factor as recommended in the EQLS guidelines. In sensitivity analyses multilevel logistic regressions were conducted without weights and with weights. The parameter estimates were substantially similar. Therefore the unweighted ORs are presented, as advised by Winship and Radbill, ${ }^{30}$ because they are more efficient and the $\mathrm{SE}$ is correct.

\section{RESULTS}

Overall, 21066 men and 22569 women participated in the study and were considered for the present analysis. Table 1 shows the distribution of sociodemographic, psychosocial and material factors and the percentage of people with poor $\mathrm{PMH}$ in each category for men and women separately. Overall, the proportion of poor PMH was higher in women than in men (30\% vs $24 \%)$. Furthermore, women in the study sample were slightly older, more often had low education, did not work, had children, practiced religion, did not engage in political participation and were affected by material deprivation.

\section{Models 1-3}

Table 2 presents the results for the multilevel logistic regression analyses, with each set of factors being studied separately for men and women. In model 1, which included sociodemographic factors, lower educational level, older age and not working were significantly associated with poor PMH among both genders. Additionally being citizen of a non-European country was associated with poor PMH in women. In model 2, including sociodemographic and psychosocial factors, living without a partner, practicing religion rarely or never, low social support, low levels of trust and high 
Sociodemographic factors

Age (years)

18-24

25-34

35-49

50-64

$65+$

Education

Primary or less

Secondary

Tertiary

Yes

No

Urbanisation level

Countryside or village

Tounn or city
Towside

Citizenship

European

Non-European

Psychosocial factor

Marital status

Living with partne

Living alone

Children

Present

Absent

Religion

Practicing often

Rarely
Never

Social network

High

Low

Social support
High

High

Low
Political participation

Yes
No

Level of trust

High

Low

Social exclusion

Low

High

Material factors

Neighborhood problems

Low

High

Housing problems

Absent

Present

1.00

1.78 (1.51 to 2.08 )

2.33 (2.00 to 2.70$)$

2.17 (1.88 to 2.50$)$

1.77 (1.52 to 2.06$)$

1.00

0.66 (0.58 to 0.74$)$

0.50 (0.43 to 0.57 )

1.00

1.66 (1.52 to 1.81$)$

1.00

1.01 (0.93 to 1.09 )

1.00

1.22 (0.94 to 1.56$)$

1.00

1.20 (1.09 to 1.31 )

1.00

0.96 (0.86 to 1.08 )

1.00

1.11 (1.00 to 1.23$)$

1.27 (1.15 to 1.41 )

1.00

1.03 (0.93 to 1.13 )

1.00

1.30 (1.20 to 1.41$)$

1.00

0.99 (0.91 to 1.08 )

1.00

1.66 (1.53 to 1.79 )

1.00

1.82 (1.68 to 1.98 )
1.00

$1.65(1.37$ to 1.98) $\quad 1.00$

$2.44(2.03$ to 2.93$) \quad 1.87(1.65$ to 2.11$)$

1.97 (1.74 to 2.24$)$

1.00

0.73 (0.64 to 0.83$) \quad 0.68$ (0.62 to 0.74$)$

0.71 (0.61 to 0.83$) \quad 0.47$ (0.42 to 0.53 )

1.00

1.27 (1.15 to 1.40$)$

1.00

1.27 (1.18 to 1.37 )

1.00

1.01 (0.95 to 1.07 )

$1.00 \quad 1.00$

$1.01(0.77$ to 1.33$) \quad 1.31$ (1.05 to 1.63$)$

1.00

1.18 (1.07 to 1.30$)$

1.00

1.00 (0.89 to 1.12$)$

1.00

1.27 (1.14 to 1.42$)$

$1.13(1.01$ to 1.26$)$

1.00

1.20 (1.10 to 1.31$)$

1.00

1.43 (1.31 to 1.55$)$

1.00

$1.73(1.59$ to 1.90$)$

$\begin{array}{ll}1.00 & 1.00 \\ 1.16(1.07 \text { to } 1.27) & 1.13(1.04 \text { to } 1.23)\end{array}$

1.00

1.00

1.40 (1.30 to 1.52$)$
1.00

$1.27(1.09$ to 1.50$)$

$1.69(1.45$ to 1.96$)$

1.85 (1.59 to 2.15$)$

2.11 (1.81 to 2.46$)$

1.00

0.76 (0.69 to 0.84$)$ 0.65 (0.58 to 0.73 )

1.00

1.13 (1.05 to 1.23$)$

1.00

1.02 (0.81 to 1.30 )

1.00

1.31 (1.23 to 1.40$)$

1.17 (1.09 to 1.25$)$

.00

0.83 (0.76 to 0.91 )

1.00

0.90 (0.82 to 0.98$)$

1.00

1.09 (1.01 to 1.17 )

1.27 (1.18 to 1.38 )

1.00

1.24 (1.14 to 1.35$)$ 1.08 (1.00 to 1.17 )

1.04 (0.96 to 1.12 )

1.00

1.44 (1.35 to 1.54$)$

1.00

1.03 (0.95 to 1.11$)$

1.00

1.51 (1.42 to 1.61$)$

1.00

1.80 (1.68 to 1.92$)$

1.32 (1.23 to 1.41$)$

1.00

1.69 (1.57 to 1.81$)$

$\begin{array}{ll}1.12(1.04 \text { to } 1.20) & 1.00 \\ 1.07(1.00 \text { to } 1.15)\end{array}$

1.00

1.00

1.52 (1.43 to 1.63$)$ 


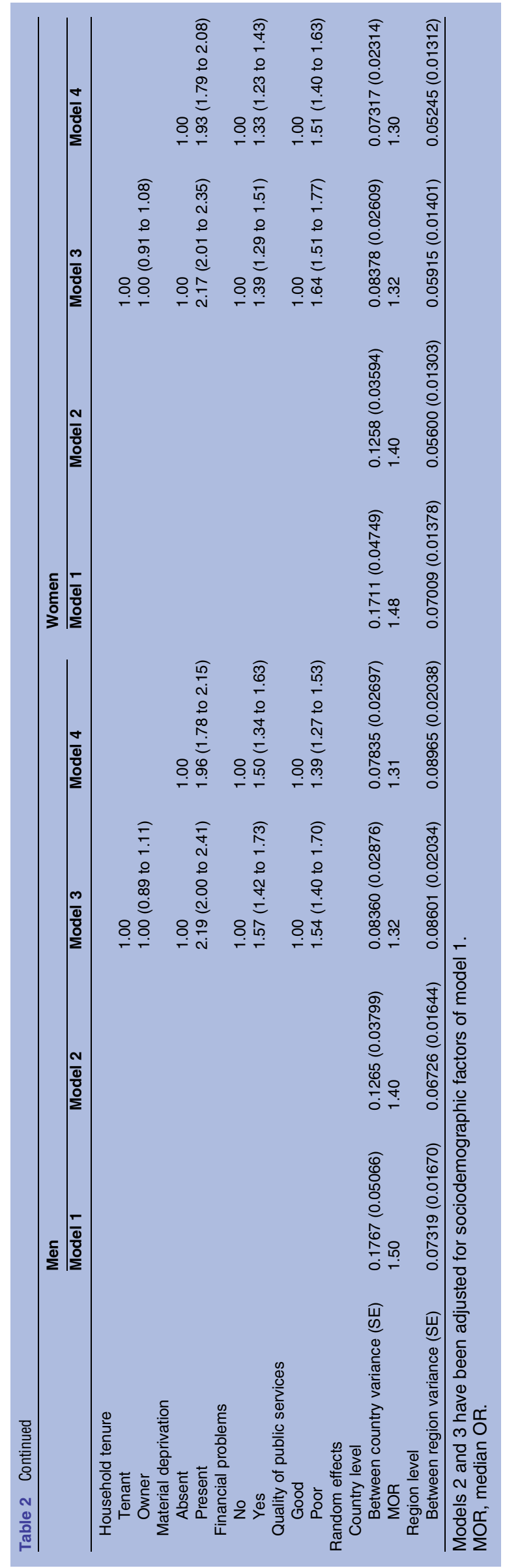

levels of social exclusion were significantly associated with poor PMH among both genders, independent of sociodemographic factors. Having no children was additionally associated with poor PMH in women. The strongest effect in model 2 was seen for high social exclusion with an OR of 1.82 (95\% CI 1.68 to 1.98) for men and 1.80 (95\% CI 1.68 to 1.92 ) for women. In model 3, including sociodemographic factors and material factors, all material factors, except household tenure, were associated with poor PMH among both genders, controlling for sociodemographic characteristics. The highest OR was seen for material deprivation in both genders: the OR for men was 2.13 (95\% CI 2.00 to 2.41) and for women was $2.17(95 \%$ CI 2.01 to 2.35$)$. Urbanisation level and social network were not associated with poor $\mathrm{PMH}$ in both genders in the respective models, and were therefore not included in model 4.

\section{Model 4}

In model 4 the strongest associations with poor PMH among both genders were observed for higher age, social exclusion (men: $\mathrm{OR}=1.73,95 \%$ CI 1.59 to 1.90 ; women: $\mathrm{OR}=1.69,95 \%$ CI 1.57 to 1.81 ) and material deprivation (men: OR=1.96, 95\% CI 1.27 to 1.53; women: $\mathrm{OR}=1.93,95 \%$ CI 1.79 to 2.08 ). Moreover, living without a partner, lower education status, not working, practicing religion rarely or never, low social support, social exclusion and all material factors were significantly associated with poor PMH among both genders. Not having children was independently associated with poor PMH in women only. Being citizen of a non-European country was no longer significant when taking into account all other factors in model 4.

\section{Country-level variation}

MOR differed only slightly between men and women, but decreased from model 1 to model 4 , where more individual-level information was included. The MOR in model 1, where sociodemographic factors are included, was 1.50 for men and 1.45 for women. However, when studying all factors together in model 4 the MOR was lower, namely 1.31 for men and 1.30 for women. Thus, country-specific variation was larger with regard to effects of sociodemographic factors on mental health, but smaller considering psychosocial (MOR=1.40 for both genders) or material factors (MOR=1.32 for both genders).

\section{DISCUSSION}

This is one of the first studies to examine PMH in a large Europe-wide sample and to the best of our knowledge the first to report on a wide range of determinants. We grouped the determinants that have individually been reported in the literature with regard to mental health. Our study found a broad range of risk factors for poor PMH and our results are mainly in line with previous research that showed similar associations in single 
countries or single correlates, not controlling for other factors. However, most studies so far have looked at mental illness and not at PMH. Other studies covering positive aspects of mental health used single questions about happiness or life satisfaction. This approach is not the same as the concept of PMH, since it only covers the hedonistic perspective of well-being, in the sense of feeling happy. ${ }^{31}$

A large number of associations between sociodemographic, psychosocial and material risk factors and $\mathrm{PMH}$ in citizens from 34 European countries were found in this study. Higher age, lower educational status and not working were associated with poor $\mathrm{PMH}$ among both genders. Of the psychosocial factors, practicing religion rarely or never, low social support, low levels of trust and high social exclusion were associated with poor PMH among both genders. Living alone was associated with PMH in both genders. Not having children had a protective effect against poor PMH for women but not for men. All material determinants were associated with poor PMH among men and women.

Our results are in line with previous studies reporting that low educational level, ${ }^{14} 32-34$ and not working, ${ }^{14} 33$ are associated with poor mental well-being. The results on age and indicators of mental well-being are controversial, some studies reporting that older age groups are at a higher risk for poor mental well-being, ${ }^{14} 163235$ which would be in accordance with our results, others finding the opposite. ${ }^{36-38}$ Associations between living area and mental well-being have been reported; however, the direction of this relationship is not clear: living in a rural area ${ }^{14}$ and living in a large city ${ }^{16}$ have been associated with poor PMH. When classifying living area into two categories-urban or rural-we did not find a significant association between living area and PMH. Living alone, ${ }^{16}{ }^{33}{ }^{35}$ low social support, $^{13}{ }^{14} 16 \quad 34 \quad 39$ loneliness $^{14}$ and exclusion ${ }^{40}$ have been associated with poor positive mental or emotional health and a study in Russia found associations between high levels of trust and high emotional health. ${ }^{40}$ We found that not or rarely attending religious services was associated with poor PMH. A previous study reported that frequency of prayer is associated with mental wellbeing. ${ }^{38}$ There are some studies investigating the associations of material factors and mental illness. Poor economic condition ${ }^{16}$ and neighbourhood problems ${ }^{15} 39$ have been associated with poor mental well-being or PMH before. However, research on the effect of other material factors on PMH is lacking.

In the intermediate models 1-3, age, social exclusion and material deprivation showed the strongest association with poor PMH among men and women. These three factors also appeared to have the strongest association with poor PMH in our final model (model 4), examining the effect of all determinants together. Particularly, all material factors were significantly associated with poor PMH in the separate as well as in the complete model, taking further sociodemographic and psychosocial factors into account. This group of determinants has not been studied extensively yet in the context of PMH but rather with regard to self-rated health $^{21}{ }^{22}$ or mental illness. ${ }^{41}$ The fact that these factors stayed significant throughout all models is in agreement with the belief that material factors may have a direct (through biological pathways) or indirect effect (through eg, behavioural factors) on health outcomes. ${ }^{22}$ We might not have found a significant association of household tenure and $\mathrm{PMH}$ because there are cultural differences between countries in the approaches of buying a house or living on rent. Hence household tenure might not be an indicator for material prosperity in all countries.

One of the limitations of this study is its cross-sectional nature. When interpreting the relationship between the determinants, it needs to be kept in mind that no causal interpretation is possible. The response rate of $41 \%$ in the third round of the EQLS was lower than aspired and differed across countries. ${ }^{18}$ It has been argued that nonparticipants may be more likely to belong to low social groups and to have poorer health outcomes. ${ }^{42}$ This would be a selection bias and the prevalence of poor $\mathrm{PMH}$ as well as the association between some determinants, especially material determinants, might be underestimated. This study did not take into account (mediating) behavioural factors (eg, physical activity), which may play a role in the association with $\mathrm{PMH}$. Physical activity has a positive effect on $\mathrm{PMH}^{43}$ and it could be hypothesised that living in areas with high neighbourhood problems might hinder leisure-time physical activity, hence physical activity could be a mediating factor in the association between material factors and PMH. For future studies it would be highly desirable to also include behavioural factors. Although the WHO-5 is a validated and relatively short measure of $\mathrm{PMH}$ in population surveys, there are more comprehensive measures to assess this complex construct, which should be used in future studies. Moreover, in this study the cut-off point for poor PMH has been set at the $25 \%$ centile to look at people who have low levels of PMH. Using medians or quartiles as cut-off points when no official cut-off points are available is common practice. However, a standardised cut-off point for the WHO-5 would be desirable. The study of PMH is relatively young and there is still discussion on a common definition of $\mathrm{PMH}$ and different measurements exist. It will take some years to achieve agreement on the appropriate measurement and definition of PMH. ${ }^{10}$ In this context it would be highly desirable to also test if instruments are gender sensitive. This study, on the other hand, has many strengths. The large dataset with comparable data across Europe, allowed us to study each gender separately and comparability of data between 34 European countries enabled us to give an overall view of determinants of PMH among people in Europe. It used the WHO-5 as a validated measure for $\mathrm{PMH}$ and has analysed a broad picture of potential risk factors. 


\section{CONCLUSION}

This study showed independent associations between various sociodemographic, psychosocial and material determinants and PMH. Our study provides the first overview of the distribution of determinants and their association with PMH in Europe. Therefore, it can be used as the basis for confirmatory and more specific analysis of determinants of poor PMH as well as for the development of preventive programmes or policies in this context.

Acknowledgements The authors gratefully acknowledge the European Foundation for the Improvement of Living and Working Conditions as the original data creators and the UK Data Archive. The European Foundation for the Improvement of Living and Working Conditions and the UK Data Archive bear no responsibility for the data analysis or interpretation.

Contributors SD was in charge of designing, analysing and writing up for the manuscript. $C B$ advised on statistical analyses and helped to draft the manuscript. GB participated in the conceptualisation of the analyses and in the revision of the manuscript. All authors read and approved the final manuscript.

Funding This research received no specific grant from any funding agency in the public, commercial or not-for-profit sectors.

\section{Competing interests None.}

Provenance and peer review Not commissioned; externally peer reviewed.

Data sharing statement We analysed data of the European Quality of Life Survey (EQLS). Permission to analyse data of the EQLS can be requested at Eurofond (http://www.eurofound.europa.eu/surveys/faq/index.htm).

Open Access This is an Open Access article distributed in accordance with the Creative Commons Attribution Non Commercial (CC BY-NC 3.0) license, which permits others to distribute, remix, adapt, build upon this work noncommercially, and license their derivative works on different terms, provided the original work is properly cited and the use is non-commercial. See: http:// creativecommons.org/licenses/by-nc/3.0/

\section{REFERENCES}

1. WHO. Strengthening mental health promotion. Fact sheet no 220. Geneva, 2001.

2. Huppert FA, Whittington JE. Evidence for the independence of positive and negative well-being: implications for quality of life assessment. Br J Health Psychol 2003;8:107-22.

3. Keyes CL. The mental health continuum: from languishing to flourishing in life. J Health Soc Behav 2002;43:207-22.

4. Keyes CLM. Mental illness and/or mental health? Investigating axioms of the complete state model of health. J Consult Clin Psychol 2005:73:539-48.

5. Hu Y, Stewart-Brown S, Twigg L, et al. Can the 12-item General Health Questionnaire be used to measure positive mental health? Psychol Med 2007;37:1005-13.

6. Ryff CD, Love GD, Urry HL, et al. Psychological well-being and ill-being: do they have distinct or mirrored biological correlates? Psychother Psychosom 2006;75:85-95.

7. Wood AM, Joseph S. The absence of positive psychological (eudemonic) well-being as a risk factor for depression: a ten year cohort study. J Affect Disord 2010;122:213-17.

8. Keyes CL, Dhingra SS, Simoes EJ. Change in level of positive mental health as a predictor of future risk of mental illness. $A m ~ J$ Public Health 2010;100:2366-71.

9. Keyes CL, Simoes EJ. To flourish or not: positive mental health and all-cause mortality. Am J Public Health 2012;102:2164-72.

10. Huppert FA, So TT. Flourishing across Europe: application of a new conceptual framework for defining well-being. Soc Indic Res 2013;110:837-61.

11. Ryan RM, Deci EL. On happiness and human potentials: a review of research on hedonic and eudaimonic well-being. Annu Rev Psychol 2001;52:141-66.

12. Tennant $R$, Hiller L, Fishwick $R$, et al. The Warwick-Edinburgh Mental Well-being Scale (WEMWBS): development and UK validation. Health Qual Life Outcomes 2007;5:63.
13. Bull T. Work life and mental well-being: single and coupled employed mothers in Southern Europe and Scandinavia. Glob Health Promot 2009;16:6-16.

14. Van Lente $\mathrm{E}$, Barry MM, Molcho M, et al. Measuring population mental health and social well-being. Int $J$ Public Health 2012;57:421-30.

15. Guite HF, Clark C, Ackrill G. The impact of the physical and urban environment on mental well-being. Public Health 2006;120: 1117-26.

16. Lehtinen V, Sohlman B, Kovess-Masfety V. Level of positive mental health in the European Union: results from the Eurobarometer 2002 survey. Clin Pract Epidemiol Ment Health 2005;1:9.

17. Eurofound. Quality of life in Europe: subjective well-being Luxembourg: Publications Office of the European Union, 2013.

18. Eurofound. Third European Quality of Life Survey-quality of life in Europe: impacts of the crisis. Luxembourg: Publications Office of the European Union, 2012.

19. World Health Organization Regional Office Europe. Well-being measures in primary health care: the Depcare project. Stockholm; 1998, Report on a WHO Meeting.

20. Bech $\mathrm{P}$, Olsen LR, Kjoller M, et al. Measuring well-being rather than the absence of distress symptoms: a comparison of the SF-36 mental health subscale and the WHO-Five well-being scale. Int $J$ Methods Psychiatr Res 2003;12:85-91.

21. Niedhammer I, Kerrad S, Schutte S, et al. Material, psychosocial and behavioural factors associated with self-reported health in the Republic of Ireland: cross-sectional results from the SLAN survey. BMJ Open 2013;3:pii: e002797.

22. Schutte S, Chastang JF, Parent-Thirion A, et al. Association between socio-demographic, psychosocial, material and occupational factors and self-reported health among workers in Europe. J Public Health (Oxf) 2013. Published Online First: 23 May 2013. doi: $10.1093 /$ pubmed/fdt050

23. Aldabe B, Anderson R, Lyly-Yrjanainen M, et al. Contribution of material, occupational, and psychosocial factors in the explanation of social inequalities in health in 28 countries in Europe. J Epidemiol Community Health 2011;65:1123-31.

24. Springer KW, Mager Stellman J, Jordan-Young RM. Beyond a catalogue of differences: a theoretical frame and good practice guidelines for researching sex/gender in human health. Soc Sci Med 2012;74:1817-24.

25. Blakely T, Subramanian SV. Multilevel studies. In: Oakes JM, Kaufman JS, eds. Methods in social epidemiology. San Francisco: Jossey-Bass, 2006:316-40.

26. Merlo J, Chaix B, Ohlsson $\mathrm{H}$, et al. A brief conceptual tutorial of multilevel analysis in social epidemiology: using measures of clustering in multilevel logistic regression to investigate contextual phenomena. J Epidemiol Community Health 2006;60:290-7.

27. Larsen K, Merlo J. Appropriate assessment of neighborhood effects on individual health: integrating random and fixed effects in multilevel logistic regression. Am J Epidemiol 2005;161:81-8.

28. Katz MH. Multilevel analysis. A parctical guide for clinicians and public health researchers. Cambridge University Press, 2011.

29. Davoren MP, Fitzgerald E, Shiely F, et al. Positive mental health and well-being among a third level student population. PLOS ONE 2013;8:e74921.

30. Winship C, Radbill L. Sampling weights and regression-analysis. Sociolog Methods Res 1994;23:230-57.

31. Waterman AS. Two conceptions of happiness: contrasts of personal expressiveness (eudaimonia) and hedonic enjoyment. J Pers Soc Psychol 1993;64:678-91.

32. Lluch-Canut T, Puig-Llobet M, Sanchez-Ortega A, et al. Assessing positive mental health in people with chronic physical health problems: correlations with socio-demographic variables and physical health status. BMC Public Health 2013;13:928.

33. Cable N, Bartley M, Chandola $\mathrm{T}$, et al. Friends are equally important to men and women, but family matters more for men's well-being. $J$ Epidemiol Community Health 2013;67:166-71.

34. Hapke U, von der Lippe E, Busch M, et al. Psychische Gesundheit bei Erwachsenen in Deutschland. Daten und Fakten: Ergebnisse der Studie "Gesundheit in Deutschland aktuell 2010": Robert Koch-Institut, 2012.

35. Dear K, Henderson S, Korten A. Well-being in Australia-findings from the National Survey of Mental Health and Well-being. Soc Psychiatry Psychiatr Epidemiol 2002;37:503-9.

36. Keyes CLM, Westerhof GJ. Chronological and subjective age differences in flourishing mental health and major depressive episode. Aging Ment Health 2012;16:67-74.

37. Esteban MM, Puerto MI, Fernández Cordero X, et al. [Determinants of poor mental health in people aged 16 to 64 residing in a large city]. An Sist Sanit Navar 2012;35:229-40. 
38. Meisenhelder JB, Chandler EN. Prayer and health outcomes in church lay leaders. West J Nurs Res 2000;22:706-16.

39. Gale CR, Dennison EM, Cooper C, et al. Neighbourhood environment and positive mental health in older people: the Hertfordshire Cohort Study. Health Place 2011;17: 867-74

40. Rose R. How much does social capital add to individual health? A survey study of Russians. Soc Sci Med 2000;51:1421-35.

41. McKenzie SK, Imlach Gunasekara F, Richardson K, et al. Do changes in socioeconomic factors lead to changes in mental health?
Findings from three waves of a population based panel study. $J$ Epidemiol Community Health 2013;68:253-60.

42. Goldberg M, Chastang JF, Leclerc A, et al. Socioeconomic, demographic, occupational, and health factors associated with participation in a long-term epidemiologic survey: a prospective study of the French GAZEL cohort and its target population. $A m \mathrm{~J}$ Epidemiol 2001;154:373-84.

43. Malcolm E, Evans-Lacko S, Little K, et al. The impact of exercise projects to promote mental wellbeing. $J$ Ment Health 2013;22:519-27. 